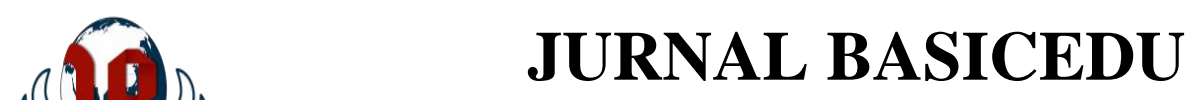

Volume 5 Nomor 2 Tahun 2021 Halaman 951 - 957

Research \& Learning in Elementary Education https://jbasic.org/index.php/basicedu

\title{
Pengembangan dan Pembinaan Karakter Siswa dengan Mengoptimalkan Peran Guru Sebagai Contextual Idol di Sekolah Dasar
}

\author{
Sedya Santosa ${ }^{1 凶}$, Seka Andrean ${ }^{2}$ \\ UIN Sunan Kalijaga Yogyakarta1,2 \\ E-mail: $\underline{\text { sedya.santosa@uin-suka.ac.id }{ }^{1}, \underline{\text { sekaandrean28@gmail.com }}{ }^{2}}$
}

\begin{abstract}
Abstrak
Guru memiliki peran utama untuk memposisikan kedudukannya sebagai tenaga pendidik yang profesional. Tujuan penelitian ini adalah untuk mengetahui peran guru sebagai contextual idol dalam membina dan mengembangkan karakter peserta didik. Metode penelitian yang digunakan yaitu pendekatan studi pustaka (library research) melalui sumber pustaka yang berhubungan dengan variabel penelitian serta sumber literatur lainnya. Kemudian dianalisis dan disajikan hasil temuan data secara objektif. Hasil penelitian menunjukkan bahwa dalam Undang-Undang guru dengan tegas mensyaratkan seorang guru harus mempunyai kepribadian atau karakter baik, harus menguasai materi pelajaran yang di ajarkan, harus bisa melaksanakan pembelajaran dan harus bermasyarakat. Adapun peran guru sebagai contextual idol dalam membina dan mengembangkan karakter peserta didik yaitu: Guru harus mempuyai karakter baik dan mampu menanamkannya, memiliki keterampilan asertif dan menyimak, mempunyai perasaan senang belajar, mengajar dengan tulus, ikhlas, dan penuh kasih sayang, menanamkan empat kata ajaib yaitu maaf, tolong, permisi, dan terimakasih, menyelengarakan suasana pembelajaran yang menyenangkan, memberikan pelayanan yang terbaik. Dengan ini, peserta didik dapat mengidolakan gurunya sendiri sebagai contextual idol.
\end{abstract}

Kata Kunci: Peran Guru, Contextual Idol, Pengembangan dan Pembinaan, Karakter.

\begin{abstract}
Teachers have a leading role to meet their position as professional educators. The purpose of this research is to know the role of teachers as contextual idols in fostering and developing the character of learners. The research method used is the library research approach through library resources related to research variables and other literature sources. Then, the findings of the data are analyzed and presented objectively. The results showed that the Teachers Law strictly require a teacher to have a personality or good character, must master the subject matter that is mastered, must be able to carry out learning and must be sociable. The role of teachers as contextual idols in fostering and developing the character of learners are: Teachers must have good character and be able to instill it, have asertif and listening skills, have a feeling of pleasure in learning, teach sincerely and affectionately, instill four magic words that are sorry, please, excuse me, and thank you, maintain a pleasant learning atmosphere, and provide the best service. As a result, students can follow their own teacher as a contextual idol.
\end{abstract}

Keywords: Teacher Role, Contextual Idol, Development and Coaching, Character.

Copyright (c) 2021 Sedya Santosa, Seka Andrean

$\triangle$ Corresponding author :

Email : sedya.santosa@uin-suka.ac.id

DOI : https://doi.org/10.31004/basicedu.v5i2.849

ISSN 2580-3735 (Media Cetak)

ISSN 2580-1147 (Media Online) 


\section{PENDAHULUAN}

Pembangunan Nasional dalam bidang pendidikan merupakan upaya mencerdaskan kehidupan bangsa dan meningkatkan kualitas manusia Indonesia yang beriman dan bertaqwa kepada Tuhan Yang Maha Esa (Ilahi dan Ratri 2012, 25). Pendidikan dapat dilakukan dengan usaha sadar dan terencana untuk mewujudkan proses pembelajaran agar peserta didik secara aktif mengembangkan potensi dirinya untuk memiliki kekuatan spiritual keagamaan, pengendalian diri, kepribadian, kecerdasan akhlak mulia, serta keterampilan yang diperlukan dirinya, masyarakat, bangsa dan negara (Munandar 2012, 6). Melalui proses pendidikan yang bermutu, suatu bangsa dapat menyongsong masa depan yang lebih baik.

Di era globalisasi sekarang ini, dunia pendidikan dihadapkan dengan berbagai tantangan dan permasalahan. Diantara permasalahannya adalah sebagaimana yang kita ketahui bahwa timbulnya berbagai macam bentuk demoralisasi. Demoralisasi inilah yang sebenarnya sebagai biang kerok terjadinya seluruh masalah yang menimpa bangsa ini, tetapi kita menganggap masalah demoralisasi adalah masalah yang kecil dan sepele. Jika kita lihat dari segi kata, arti demoralisasi adalah kemerosotan akhlak atau kerusakan moral.

Kemerosotan akhlak pada peserta didik disebabkan karena kurang tertanamnya pendidikan agama yang kuat. Ada beberapa faktor yang menyebabkan kurang tertanamnya pendidikan agama yang kuat bagi anak yaitu dari faktor keluarga, lingkungan, dan sekolah. Selain kurangnya pendidikan agama bagi anak ada faktor lain yaitu kurangnya pembinaan dan pengembangan karakter yang dilakukan sejak dini (Wati dan Arif 2017, 60). Dalam konteks demikian, sekolah merupakan wahana dalam pengembangan dan pembinaan karakter peserta didik setelah memasuki usia sekolah.

Di sekolah, peran guru sangat penting dan strategis dalam pengembangan dan pembinaan karakter peserta didik. Guru memiliki peran aktif untuk memposisikan kedudukannya sebagai tenaga pendidik yang profesional, serta tidak semata-mata hanya mentransfer ilmu pengetahuannya saja, melainkan harus dapat menjadi seorang pendidik dan pembimbing yang mampu menyampaikan arahan serta menuntun peserta didik ketika sedang belajar (Hadari 2015, 123). Oleh sebab itu, seorang pendidik dapat optimal dalam menjalankan tugas tanggungjawabnya dengan baik. Tanggungjawab seorang pendidik selain untuk menjalin interaksi yang baik terhadap peserta didiknya, hendaknya seorang pendidik juga harus bertanggungjawab untuk mengembangkan dan membina peserta didik dalam berperilaku berkarakter. Hal ini sejalan dengan penelitian Natalini (2020) yang berpendapat bahwa pelaksanaan program pendidikan karakter didukung oleh banyak faktor, antara lain keadaan lingkungan belajar, lingkungan sosial, dan cara mengasuh anak. Rencana pendidikan karakter sangat baik, dan penting untuk terus dilaksanakan dan dikembangkan, karena berdampak positif pada pembentukan karakter siswa dan nilai akademik siswa.

Dengan demikian, peran guru sangat penting dan strategis untuk pembinaan dan pengembangan karakter peserta didik di sekolah. Sebagai sosok orang tua kedua di sekolah, guru bisa menjadi mood atau idola kontekstual (contextual idol) bagi peserta didik-peserta didiknya. Hal ini sejalan dengan UU No. 20 Tahun 2003 tentang Sistem Pendidikan Nasional (SISDIKNAS) Pasal 4 ayat 4 tentang prinsip penyelengaraan pendidikan menyebutkan "pendidikan diselenggarakan dengan memberikan keteladanan, membangun kemauan, dan mengembangkan kreativitas peserta didik dalam proses pembelajaran" (Anonim 2003). Dengan ini, jelas bahwa tugas guru bukan hanya mengajar, tetapi juga sebagai pendidik yang harus bisa menjadi contoh, maupun suri tauladan yang baik bagi peserta didiknya.

Dengan demikian, guru adalah pribadi yang profesional dan berwawasan luas, serta menularkan ilmunya kepada orang lain sehingga dapat meningkatkan kualitas sumber daya manusianya. Kebajikan guru dikaitkan dengan tugas mulia yang telah dia lakukan. 
DOI : https://doi.org/10.31004/basicedu.v5i2.849

\section{METODE PENELITIAN}

Penelitian ini menggunakan jenis penelitian kualitatif. Metode yang digunakan ialah metode study kepustakaaan (library research) (Arikunto 2013, 172). Yakni dengan cara memadukan data dari bermacammacam sumber literatur dengan cara meliputi buku-buku, jurnal, prosiding seminar nasional, dan artikelartikel ilmiah yang berhubungan dengan peran guru sebagai contextual idol dalam mengembangkan dan membina karakter siswa. Kemudian, menganalisis serta mengkaji teori-teori yang berkaitan. Penulis menyajikan hasil temuan data secara objektif dan sistematis melalui teknik analisis deskriptif data (Sukmadinata 2013, 86).

\section{HASIL DAN PEMBAHASAN}

\section{Pendidikan Karakter}

Kata karakter berasal dari bahasa Yunani "to mark" yang berarti menandai atau memfokuskan, bagaimana mengaplikasikan nilai kebaikan dalam bentuk tindakan atau tingkah laku. Oleh sebab itu, seseorang yang berperilaku tidak jujur, kejam, atau rakus dikatakan sebagai orang yang berkarakter jelek, sementara seoarang yang berperilaku jujur, suka menolong dikatakan sebagai orang yang berkarakter mulia (Zubaedi 2012, 8). Jadi istilah karakter erat kaitanya dengan personality (kepribadian) seseorang individu. Seseorang bisa disebut orang yang berkarakter (a person of character) apabila perilakunya sesuai dengan kaidah moral (Andrean dan Muqowim 2020, 47). Selanjutnya Hornby dan Parnwell mengatakan bahwa karakter adalah kualitas, nama, atau reputasi spiritual atau moral. Hermawan Kertajaya mengartikan peran sebagai karakteristik yang dimiliki oleh suatu objek atau individu. Karakteristik ini nyata, berakar pada kepribadian objek atau individu, dan merupakan mesin pendorong bagaimana seseorang bertindak, bertindak, berbicara, dan merespons (Majid 2011, 11).

Menurut Kementerian Pendidikan Nasional, karakter adalah cara berpikir dan berperilaku yang mewujudkan karakteristik setiap orang yang hidup dan bekerja sama dalam lingkungan keluarga, masyarakat, bangsa, dan negara. Orang yang berkarakter baik adalah orang yang dapat membuat keputusan dan bersedia bertanggung jawab atas keputusan apa pun yang mereka buat (Hariyanto, M.S 2012, 42). Menurut Thomas Lickona, siswa perlu menanamkan tujuh nilai kepribadian, antara lain: kejujuran atau kejujuran, kasih sayang, keberanian, kasih sayang, pengendalian diri, kerja sama, dan kerja keras. Pendidikan karakter sangat erat kaitannya dengan teori pembelajaran behavioris, karena tujuan dari pendidikan karakter sama dengan teori ini, yaitu mengubah perilaku siswa yang buruk (Muttaqin dan Hariyadi 2020, 2).

Seperti yang terlihat dari beberapa penjelasan di atas, dapat disimpulkan bahwa pendidikan karakter merupakan upaya sadar dan ikhlas dari guru untuk menanamkan nilai-nilai kepada siswa. Orang yang berkarakter baik adalah mereka yang berusaha melakukan yang terbaik untuk Tuhan Yang Maha Esa, dirinya sendiri, orang lain, lingkungan, negara dan negaranya dengan memanfaatkan sepenuhnya potensi (ilmu) yang dimilikinya dan disertai dengan kesadaran dan emosi (perasaannya).

\section{Peran Guru}

Guru berperan penting dalam mendidik, mmbimbing dan membimbing peserta didik di lingkungan sekolah. Hal ini dianggap sangat penting karena guru yang sering bersentuhan langsung dengan guru selama proses pembelajaran (Nanang Yuhana dan Aisah Aminy 2019, 117). Sedangkan W.F Connell dalam Sudarwan Danim membedakan tujuh peran seorang guru yaitu (1) pendidik (nurturer), (2) model, (3) pengajar dan pembimbing, (4) pelajar (learner), (5) komunikator terhadap masyarakat setempat, (6) pekerja administrasi, serta (7) kesetiaan terhadap lembaga (Danim 2010, 86). Oleh karena itu, tugas guru dapat disebut 
dengan pendidikan dan pengasuhan anak. Guru adalah sebagai penanggung jawab disiplin anak harus mengontrol aktivitas setiap anak agar tingkat perilaku anak tidak menyimpang dari norma yang ada.

Didalam proses belajar guru berperan sebagai perantara atau medium. Peserta didik harus berusaha sendiri mendapatkan suatu pengertian atau insight, sehingga timbul perubahan dalam pengetahuan, tingkah laku, dan sikap. (1) Guru sebagai pembimbing, untuk membawa peserta didik peserta didik kearah kedewasaan, pendidik tidak maha kuasa, tidak dapat membentuk anak menurut sekehendaknya; (2) Guru sebagai penghubung antara peserta didik yang nantinya akan hidup dan bekerja, serta mengabdikan diri dalam masyarakat Negara dan bangsa, dengan demikian peserta didik harus dilatih dan dibiasakan di bawah pengawasan guru di sekolah; (3) Guru sebagai penegak disiplin guru menjadi contoh-teladan dalam segala hal tata tertib baik yang berlaku di sekolah maupun yang terdapat di lingkungan masyarakat; (4) Guru sebagai administrator dan manajer, (5) Guru sebagai fasilitator, (6) Guru sebagai mediator, (7) Guru sebagai inspirator, (8) Guru sebagai korektor, (9) Guru sebagai evaluator (Darmadi 2016, 165), (10) Guru sebagai motivator (Manizar 2015, 182).

Berkaitan hal tersebut, guru sebagai pelaku utama dalam penerapan program pendidikan di sekolah dan memiliki peran yang sangat penting untuk mencapai tujuan pendidikan (Juhji 2016, 53).

\section{Contextual Idol}

Kontektual dari bahasa latin contexere artinya yaitu menjalin makna, sedangkan idol atau idola adalah sosok yang mampu memberikan inspirasi kehidupan memberdayakan dan sentuhan-sentuhan emosional yang mampu memberikan penguatan (Sukarti 2013, 472). Moh. Uzer Usman (2017) menegaskan, guru harus mampu memposisikan diri sebagai orang tua kedua siswa. Dia harus bisa menarik simpati menjadikannya idola bagi para pelajar. Pelajaran apa pun yang diambil guru harus dapat memotivasi siswa secara mendalam belajar. Dengan kata lain, ketika penampilan seorang guru tidak lagi menarik, kegagalan pertamanya adalah tidak bisa tanam benih ajarannya di antara murid-muridnya. Siswa akan enggan menghadapi guru yang tidak menarik.

Sebagai seorang idola, guru harus memiliki kepribadian yang dapat dijadikan figure. Itulah kesan yang harus dimunculkan oleh seorang guru sebagai sosok yang ideal (Rimang 2011, 39). Sedikit saja guru melakukan kesalahan, akibatnya sangat fatal bagi perkembangan jiwa anak didik. Sebagaimana pribahasa, "guru kencing berdiri, murid kencing berlari".

Dengan mengoptimalkan peran guru sebagai contextual idol dalam pendidikan karakter sejalan dengan sifat-sifat anak usia sekolah dasar. Anak-anak mempunyai sifat sebagai berikut:

1. Sifat imitasi, yaitu sifat meniru perbuatan atau kebiasaan orang lain. Dari dorongan inilah anak-anak memperoleh sebagian besar pelajaran yang dipelajari, termasuk pendikan karakter. Dorongan meniru dapat memperkuat kepatuhan.

2. Sifat identifikasi, yaitu sifat menyamakan diri atau merasa sama dengan orang lain. Anak pada umumnya akan menyamakan diri dengan ayah ibu jika berada dilingkungan keluarga, sedangkan jika berada di lingkungan sekolah anak akan menyamakan dirinya dengan guru. Hubungan yang dibangun berdasarkan identifikasi sangatlah berguna dalam menambah kepatuhan.

3. Sifat sugestible, yaitu sifat anak yang mudah dipengaruhi. Mereka pemikirannya masih sederhana sehingga mempunyai kepercayaan bulat terhadap oarang tua atau guru. Ini menjadi alat penolong untuk mengajurkan anak menjadi patuh. 
DOI : https://doi.org/10.31004/basicedu.v5i2.849

\section{Mengoptimalkan Peran Guru Sebagai Contextual Idol dalam Pembinaan dan Pengembangan Karakter Siswa di Sekolah Dasar}

Guru sebagai pendidik merupakan faktor penentu keberhasilan setiap usaha pendidikan (Hazmi 2019, 58). Menurut Undang-Undang Sistem Pendidikan Nasional Nomor 20 Tahun 2003, Bab 11, Pasal 39 ayat 2, Pendidik adalah tenaga profesional yang harus mempunyai kepribadian atau karakter yang baik, bertanggung jawab untuk merencanakan dan melaksanakan proses pembelajaran, mengevaluasi hasil pembelajaran, melakukan penyuluhan dan pelatihan, serta melakukan penelitian dan pengabdian kepada masyarakat (Anonim 2003, 15). Dengan kompetensi kepribadian yang dimiliki oleh seorang guru, sejak awal guru sudah memiliki modal menjadi contextual idol dalam membina dan mengembangkan karakter peserta didik di sekolah.

Agar peran guru sebagai contextual idol dalam pembinaan dan pengembang karakter peserta didik disekolah dapat berjaan dengan optimal, hal yang perlu dilakukan di antaranya sebagai berikut:

1. Guru harus mempuyai karakter yang baik dan harus mampu menanamkan pendidikan karakter pada peserta didiknya. Jika seorang guru karakternya baik, maka peserta didik akan meniru dan mengidentifikasi karakter baik yang di amati dari gurunya.

2. Guru perlu memiliki keterampilan asertif dan menyimak. Keterampilan asertif dilakukan dengan cara mengemukakan pendapat dengan hal-hal yang tidak melukai perasaan orang lain terkhusus peserta didiknya. Keterampilan minyimak dilakukan dengan cara mendengarkan dengan penuh pemahaman dan secara kritis.

3. Good teacher is a good leaner. Sebagai seorang guru harus mempunyai perasaan senang belajar dan memiliki wawasan yang luas (termasuk pendidikan karakter). Di dalam kelas seorang guru sebaiknya selalu ceria, optimis, dan cekatan.

4. Sebagai seorang guru harus mengajar dengan tulus, ikhlas, dan penuh kasih sayang. Kasih sayang ikhlas dari seorang guru kepada peserta didik akan menyebar dan gaungnya terasa sampai ke jiwa. Mereka akan merasa dicintai, disayangi, dan dihargai. Ada beberapa hal yang sukai peserta didik tentang gurunya: a) Tidak suka marah; b) Sabar; c) Harmonis; d) Menerangkan materi dengan jelas; e) Mau membantu peserta didik; f) Berhubungan akrab dengan peserta didik; g) Perhatian pada peserta didik; h) Adil, tidak pilih kasih; i) jujur; j) Tegas tapi tidak kaku; k) Memiliki disiplin tinggi; 1) Menguasai materi, dan lain-lain.

5. Guru menyadari bahwa sebagai pendidik memiliki kewajiban menananamkan vale atau nilai (akhlak karimah). Setidaknya, ada empat karakter yang harus ditanamkan guru kepada anak didik: jujur (berhubungan dengan SQ), cerdas (berhubungan dengan IQ), peduli (berhubungan dengan EQ), tangguh (berhubungan dengan AQ).

6. Tanamkan empat kata ajaib yang harus sering digunakan oleh guru, yaitu maaf, tolong, permisi, dan terima kasih. Setelah melakukan pembelajaran di kelas, biasakan peserta didik membuat refleksi, baik lisan maupun tulisan kesan, pesan, dan perasaan mereka terhadap pembelajaran hari itu. Serta jangan lupa seorang guru harus segera merespon dengan menjawab atau membalas pertanyaan dari peserta didiknya. Hal ini merupakan ajang interaksi personal yang dapat meningkatkan kedekatan secara emosional antara guru dan peserta didik.

7. Guru idola biasanya juga merupakan guru yang mengispirasi yaitu bisa membuat peserta didiknya ingin seperti sosok guru yang di idolakan, tentunya dengan semua hal-hal positif yang dimiiki oleh guru tersebut. 
8. Guru idola berusaha menyelenggarakan suasana pembelajaran yang menyenangkan dan menantang. Hal itu dapat ditempuh dengan ice breaking yang bisa kita sisipkan dengan game atau permainan dalam pembelajaran di dalam atau luar kelas. Dengan demikian, guru berusaha menyatukan pikiran dalam jiwa dengan peserta didik hingga terjain kebersamaan dan memahami satu sama lain.

9. Sebagai seorang guru, harus memberikan pelayanan yang terbaik dan memuaskan kepada peserta didiknya, agar mereka senang dan semangat dalam proses pembelajaran di kelas. Usahakan pula peserta didik mendapat learning by doing atau belajar sambil memperhatikan sehingga pembelajaran menjadi lebih bermakna.

\section{KESIMPULAN}

Dengan kompetensi guru yang dipersyaratkan Undang-Undang dan legalitas label guru sebagai tenaga pendidik yang profesional, hal inilah yang menjadikan seorang guru untuk menjalankan perannya sebagai contextual idol bagi peserta didiknya di sekolah. Adapun peran guru sebagai contextual idol dalam pembinaan dan pengembang karakter peserta didik dapat optimal, hal yang perlu dilakukan yaitu: Guru harus mempuyai karakter baik dan mampu menanamkan karakter pada peserta didik, guru perlu memiliki keterampilan asertif dan menyimak, guru harus mempunyai perasaan senang belajar dan memiliki wawasan, guru harus mengajar dengan tulus, ikhlas, dan penuh kasih sayang, guru harus memiliki kewajiban dalam menananamkan vale atau nilai (akhlak karimah), menanamkan empat kata ajaib yaitu maaf, tolong, permisi, dan terimakasih, guru dapat membuat peserta didiknya ingin seperti sosok guru yang di idolakan, guru harus menyelengarakan suasana pembelajaran yang menyenangkan dan menantang, guru harus memberikan pelayanan yang terbaik. Dengan hal ini, peserta didik tidak perlu lagi mengidolakan tokoh-tokoh dalam film, artis ataupun public figure lainnya. Peserta didik dapat mengidolakan gurunya sendiri sebagai contextual idol.

\section{DAFTAR PUSTAKA}

Andrean, Seka, dan Muqowim Muqowim. 2020. "Upaya Guru Dalam Membiasakan Karakter Melalui Pembelajaran Aqidah Akhlak Di MI Ma’arif." Al-Adzka: Jurnal Ilmiah Pendidikan Guru Madrasah Ibtidaiyah 10 (1): 43-52..

Anonim. 2003. Undang-Undang No. 20 Tahun 2003 Tentang SISDIKNAS dan Penjelasannya. Yogyakarta: Media Wacana Press.

Arikunto, Suharsimi. 2013. Prosedur Penelitian Suatu Pendekatan Praktis. Jakarta: Rineka Cipta.

Danim, Sudarwan. 2010. Inovasi Pendidikan dalam Upaya Peningkatan Profesionalisme Tenaga Kependidikan. Bandung: Pustaka Setia.

Darmadi, Hamid. 2016. "Tugas, Peran, Kompetensi, Dan Tanggung Jawab Menjadi Guru Profesional." Edukasi: Jurnal Pendidikan 13 (2): 161-74.

Hadari, Nawawi. 2015. Organisasi Sekolah dan Pengelolaan Kelas Sebagai Lembaga Pendidikan. Jakarta: CV. Haji Masagung.

Hariyanto, M.S, Muchlas Samani. 2012. Konsep dan Model Pendidikan Karakter. Bandung: PT Remaja Rosdakarya.

Hazmi, Nahdatul. 2019. "Tugas Guru Dalam Proses Pembelajaran.” JOEAI:Journal of Education and Instruction 2 (1): 56-65.

Ilahi, Muhammad Takdir, dan Rose Kusumaning Ratri. 2012. Revitalisasi pendidikan berbasis moral. Yogyakarta: Ar-Ruzz Media. 
DOI : https://doi.org/10.31004/basicedu.v5i2.849

Juhji, Juhji. 2016. “Peran Urgen Guru Dalam Pendidikan.” Studia Didaktika 10 (01): 51-62.

Majid, Abdul. 2011. Pendidikan Karakter Persfektif Islam. Bandung: PT Remaja Rosdakarya.

Manizar, Elly. 2015. "Peran Guru Sebagai Motivator Dalam Belajar.” Tadrib 1 (2): 204-22.

Munandar, Utami. 2012. Pengembangan kreativitas anak berbakat. Jakarta: Departemen Pendidikan \& Kebudayaan : Reneka Cipta.

Muttaqin, Muhammad Fauzan, dan Slamet Hariyadi. 2020. "Implementasi Penguatan Pendidikan Karakter Berbasis Lingkungan Masyarakat Pada Sekolah Dasar." JRPD (Jurnal Riset Pendidikan Dasar) 3 (1): $1-7$.

Nanang Yuhana, Asep, dan Fadlilah Aisah Aminy. 2019. "Optimalisasi Peran Guru Pendidikan Agama Islam Sebagai Konselor Dalam Mengatasi Masalah Belajar Siswa | Jurnal Penelitian Pendidikan Islam.”

Natalini, Betles, dan Agustina Tyas Asri Hardini. 2020. "Implementasi Program Pendidikan Karakter Di Sd Kanisius Gendongan Salatiga.” JRPD (Jurnal Riset Pendidikan Dasar) 3 (1): 77-86.

Rimang, Siti Suwadah. 2011. Meraih Predikat Guru dan Dosen Paripurna. Bandung: Alfabeta.

Sukarti, Margaretha Sri. 2013. "Implementasi Edutainment Untuk Menjadi Guru Idola." INSANIA: Jurnal Pemikiran Alternatif Kependidikan 18 (3): 471-82.

Sukmadinata, Nana Syaodih. 2013. Metode Penelitian Pendidikan. Bandung: PT Remaja Rosdakarya.

Usman, Moh Uzer. 2017. Menjadi Guru Profesional. Cet. Ke-29. Bandung: PT Remaja Rosdakarya.

Wati, Dian Chrisna, dan Dikdik Baehaqi Arif. 2017. "Penanaman Nilai-Nilai Religius Di Sekolah Dasar Untuk Penguatan Jiwa Profetik Siswa." 60-63. Yogyakarta, Indonesia.

Zubaedi. 2012. Desain Pendidikan Karakter. Cet. Ke-2. Jakarta: Kencana Prenada Media Group. 